\title{
CARDIAC BIOMARKER PROFILING IN EVALUATION OF RISK IN ACUTE CORONARY SYNDROME
}

\author{
May Mahmoud Sami Ibrahim, Msc; Ahmed Mohamed Gab-Allah, MD; Ola Aly Hussein, MD; and \\ Montaser Mostafa Alcekelly, MD* \\ Clinical \& Chemical Pathology and Cardiology Departments, Zagazig Faculty of Medicine, Zagazig; \\ Egypt.
}

\begin{abstract}
Background: The significance of the contribution of laboratory medicine to clinical cardiology has grown in importance over the years. This is witnessed by the recent incorporations of biomarkers into new international
\end{abstract} guidelines and in the re-definition of myocardial infarction (MI).

Aim of the work: The aim of this study is to evaluate the most important cardiac biomarker in risk evaluation in patients presenting by symptoms of cardiac ischemia. cTnT, HsCRP, pro-BNP and GDF-15 will be assayed to correlate their levels with known clinical and angiographic risk factors.

Subjects \& Methods: The study subjects included 80 adult subjects. They were divided into the following groups: Group (I) STEMI: 30 subjects, group (II) Non STEMI: 30 subjects and group (III) controls: 20 healthy volunteers age and sex matched.

Results: cTnT showed statistically significant difference between the three studied groups. As regard hsCRP and pro-BNP, there was a statistically significant difference between group (I\&III) and group (II\&III). As regard GDF-15, there was a non-statistically significant difference between the three studied groups. When both patient groups were compared regarding angiographic findings, patients of NSTEMI group showed higher percent of having multi-vessel disease than those of STEMI group.

Conclusion: All studied biochemical markers except GDF-15 showed a statistically significant difference between cases and controls, while only troponin $\mathrm{T}$ showed a statistically significant difference between both patient groups.

Key words: acute coronary syndrome, STEMI, NSTEMI, biomarkers, GDF-15.

Corresponding Author: May Mahmoud Sami Ibrahim.

Tel: 01001652221

E-mail: clinical_pathology_2010@yahoo.com.

\section{INTRODUCTION}

C oronary syndrome is associated with poor clinical outcomes, and searching for biomarkers to better guide therapy have the potential to improve clinical diagnosis of this condition. There are currently no well-defined biomarkers of response to treatment that can be used to guide management or evaluate recovery in this patient population. Development of noninvasive monitoring strategies would provide several advantages over current standard of care. At present, clinical observation and monitoring of laboratory variables form the mainstay of patient evaluation; however, these have demonstrated limited reliability ${ }^{[1]}$.

Novel biomarkers that can facilitate interventions to prevent the progression of the disease to a severe form are desired and needed. This will reduce the use of unnecessary resources in the workup of patients and avoid inappropriate discharges. In this scenario, biomarker profiles with the ability to reliably discriminate ischemic from non-ischemic patients would be of inordinate value, and could have important clinical implications in daily practice $^{[2]}$.

The significance of the contribution of laboratory medicine to clinical cardiology has grown in importance over the years. This is witnessed by the recent incorporations of biomarkers into new international guidelines and in the re-definition of myocardial infarction (MI). There are mainly two classes of indicators: markers of early injury/ischemia and markers of inflammation, coronary plaque instability and disruption ${ }^{[3]}$.

The aim of this work is to evaluate the importance of various cardiac biomarkers namely cTnT, HsCRP, proB-NP and GDF-15 in risk evaluation in patients presenting by 
symptoms of cardiac ischemia by correlating their levels with known clinical and angiographic risk factors.

\section{SUBJECTS \& METHODS}

This study included 80 adult subjects. They were divided into the following groups. Group (I): STEMI (ST-segment elevation myocardial infarction): 30 adult patients. Group (II): Non STEMI: 30 adult patients admitted to the CCU of Zagazig University Hospitals over a period from February 2015 till June 2016. Group (III): Control group: 20 apparently healthy adult subjects.

\section{Inclusion \& exclusion criteria:}

In this study patients with any systemic infection, collagen vascular disease, incomplete data or exposed to intervention procedure (e.g. primary $\mathrm{PCI}$ ) were excluded. After that all patients with STEMI or NSTEMI were included.

All individuals in this study were subjected to detailed personal history taking, and full clinical examination. Daily ECG, echocardiography and angiography were performed for patients.

Laboratory investigations for assessment of cTnT, random blood sugar, lipid profile, kidney and liver function tests. Specific investigation including assessment of High sensitivity Creactive protein (HsCRP), B-type natriuretic peptide (NT-pro BNP), and growth differentiation factor-15 (GDF-15) were performed after informed consent.

Assay:

Samples were collected and allowed to clot, then centrifuged $\sim 3000 \mathrm{rpm}$ for $20 \mathrm{~min}$. to remove the clot, then stored at $-80{ }^{\circ} \mathrm{C}$ until use. Hs-CRP was measured on full automated Cobas 6000. Test principle is particle enhanced immuno-turbidimetric assay. Human CRP agglutinates with latex particles coated with monoclonal anti-CRP antibodies and both cTnT and NT-proBNP were measured on full automated Cobas e411. Test principle is electro-chemiluminescence immunoassay.

GDF-15 was assayed by double-antibody sandwich enzyme-linked immunosorbent assay (ELISA) using Sun Red human GDF15 ELISA Kit. Adding serum to monoclonal antibody enzyme well which is precoated with human GDF-15 monoclonal antibody, incubation; then add GDF-15 antibodies labeled with biotin, and combined with Streptavidin-HRP to form immune complex; then carry out incubation and washing again to remove the uncombined enzyme. Then add chromogen solution A, B, the color of the liquid changes into the blue and at the effect of acid, the color finally becomes yellow. The chroma of color and the concentration of the human substance GDF-15 of sample were positively correlated. 


\section{RESULTS}

Table (1): Comparison between STEMI, NSTEMI and control groups as regard markers of myocardial injury

\begin{tabular}{|c|c|c|c|c|c|}
\hline $\begin{array}{c}\text { Markers of } \\
\text { myocardial injury }\end{array}$ & $\begin{array}{l}\text { Group (I) } \\
(\text { No.=30) }\end{array}$ & $\begin{array}{r}\text { Group (II) } \\
(\text { No. }=30)\end{array}$ & $\begin{array}{c}\text { Group (III) } \\
(\text { No. }=20)\end{array}$ & $\begin{array}{l}\mathrm{KW} \\
\text { test }\end{array}$ & $\begin{array}{c}\mathrm{p}- \\
\text { value }\end{array}$ \\
\hline \multicolumn{6}{|l|}{ Troponin T (pg/ml) } \\
\hline Median & 6450 & 5345.50 & 3.43 & \multirow[t]{2}{*}{45.221} & \multirow{2}{*}{$\begin{array}{c}<0.001 \\
(\mathrm{HS})\end{array}$} \\
\hline Range & $(29.9-300216)$ & $(128-110200)$ & $(3.00-5.12)$ & & \\
\hline \multicolumn{6}{|l|}{ hsCRP (mg/l) } \\
\hline Median & 9.29 & 23.31 & 1.93 & \multirow[t]{2}{*}{33.189} & \multirow{2}{*}{$\begin{array}{l}<0.001 \\
\text { (HS) }\end{array}$} \\
\hline Range & $(1.55-141.9)$ & $(0.13-153.3)$ & $(0.15-4.99)$ & & \\
\hline \multicolumn{6}{|l|}{ ProBNP (pg/ml) } \\
\hline Median & 1482 & 1487.50 & 17.66 & \multirow[t]{2}{*}{39.707} & $<0.001$ \\
\hline Range & $(6.59-25517)$ & $(40.78-33084)$ & $(5-52.44)$ & & (HS) \\
\hline \multicolumn{6}{|l|}{ GDF-15 (ng/l) } \\
\hline Median & 873.89 & 820.30 & 757.73 & \multirow[t]{2}{*}{5.138} & \multirow{2}{*}{$\begin{array}{l}0.077 \\
\text { (NS) }\end{array}$} \\
\hline Range & $(195.90-16204)$ & $(645.50-16711)$ & $(598.90-1741)$ & & \\
\hline
\end{tabular}

- Kraskall Wallis H test.

Table (2): Post hoc test for comparison between STEMI, NSTEMI and control groups as regard markers of myocardial injury

\begin{tabular}{lccc}
\hline \multicolumn{1}{c}{ Markers of myocardial injury } & $\begin{array}{c}\text { Group (I) } \\
\text { vs } \\
\text { Group (II) }\end{array}$ & $\begin{array}{c}\text { Group (I) } \\
\text { vs } \\
\text { Group (III) }\end{array}$ & $\begin{array}{c}\text { Group (II) } \\
\text { vs } \\
\text { Group (III) }\end{array}$ \\
\hline Troponin T (pg/ml) & $0.038(\mathrm{~S})$ & $0.004(\mathrm{~S})$ & 0.008 (S) \\
\hline hsCRP $(\mathrm{mg} / \mathrm{l})$ & $0.371(\mathrm{NS})$ & $0.002(\mathrm{~S})$ & $<0.001(\mathrm{HS})$ \\
\hline ProBNP $(\mathrm{pg} / \mathrm{ml})$ & $0.889(\mathrm{NS})$ & $0.026(\mathrm{~S})$ & $0.023(\mathrm{~S})$ \\
\hline GDF-15 (ng/l) & $0.987(\mathrm{NS})$ & $0.126(\mathrm{NS})$ & $0.104(\mathrm{NS})$ \\
\hline
\end{tabular}

Values (String): p-value (Sig.), $\bullet$ Tamhane T2 test.

Table (3): Comparison between STEMI and NSTEMI groups as regard number of affected vessels

\begin{tabular}{|c|c|c|c|c|c|c|}
\hline \multirow[b]{2}{*}{ Number of affected vessels } & \multicolumn{2}{|c|}{ STEMI $(N=30)$} & \multicolumn{2}{|c|}{ NSTEMI $(\mathrm{N}=30)$} & \multirow{2}{*}{ Test } & \multirow[b]{2}{*}{$\mathrm{p}$-value } \\
\hline & No. & $\%$ & No. & $\%$ & & \\
\hline One vessel & 14 & $46.7 \%$ & 12 & $40 \%$ & \multirow{3}{*}{9.725} & \multirow{3}{*}{$0.008(\mathrm{~S})$} \\
\hline Two vessels & 11 & $36.7 \%$ & 3 & $10 \%$ & & \\
\hline MVD & 5 & $16.7 \%$ & 15 & $50 \%$ & & \\
\hline
\end{tabular}

$\$$ Chi-square test, $\mathrm{p}<0.05$ is significant. 
Table (4): Comparison between one vessel, two vessels and MVD as regard markers of myocardial injury.

\begin{tabular}{|c|c|c|c|c|c|}
\hline $\begin{array}{c}\text { Markers of myocardial } \\
\text { injury }\end{array}$ & $\begin{array}{c}\text { One vessel } \\
(\text { No. }=26)\end{array}$ & $\begin{array}{c}\text { Two vessels } \\
(\text { No. }=14)\end{array}$ & $\begin{array}{c}\text { MVD } \\
(\text { No. }=20)\end{array}$ & $\begin{array}{l}\mathrm{KW} \\
\text { test }\end{array}$ & $\begin{array}{c}\text { p-value } \\
\text { (Sig.) }\end{array}$ \\
\hline \multicolumn{6}{|l|}{ Troponin T (pg/ml) } \\
\hline Median & 6450 & 2076 & 5456 & \multirow[t]{2}{*}{1.849} & \multirow{2}{*}{$\begin{array}{l}0.397 \\
(\mathrm{NS})\end{array}$} \\
\hline Range & $(29.89-292900)$ & $(30.38-80000)$ & $(128-300216)$ & & \\
\hline \multicolumn{6}{|l|}{ hsCRP (mg/l) } \\
\hline Median & 19.27 & 7.95 & 13.21 & \multirow[t]{2}{*}{2.161} & \multirow{2}{*}{$\begin{array}{c}0.339 \\
(\mathrm{NS})\end{array}$} \\
\hline Range & $(1.55-141.90)$ & $(0.13-121.50)$ & $(0.45-153.30)$ & & \\
\hline \multicolumn{6}{|l|}{ ProBNP (pg/ml) } \\
\hline Median & 710.90 & 907.55 & 1866 & \multirow[t]{2}{*}{4.358} & 0.113 \\
\hline Range & $(6.59-5053)$ & $(118.80-15267)$ & $(91.44-33084)$ & & $(\mathrm{NS})$ \\
\hline \multicolumn{6}{|l|}{ GDF-15 (ng/l) } \\
\hline Median & 943.24 & 857.30 & 782.28 & \multirow[t]{2}{*}{2.509} & 0.285 \\
\hline Range & $(646.1-16318)$ & $(591-2517)$ & $(195.90-16711)$ & & (NS) \\
\hline
\end{tabular}

- Kraskall Wallis H test.

Table (5): Markers of myocardial injury as predictor for more than one vessel disease; ROC curve Analysis

\begin{tabular}{lccccccc}
\hline $\begin{array}{c}\text { Cut-off } \\
\text { values }\end{array}$ & $\begin{array}{c}\text { SN \% } \\
(95 \% \mathrm{CI})\end{array}$ & $\begin{array}{c}\text { SP } \% \\
(95 \% \mathrm{CI})\end{array}$ & $\begin{array}{c}\text { PPV } \% \\
(95 \% \mathrm{CI})\end{array}$ & $\begin{array}{c}\text { NPV \% } \\
(95 \% \mathrm{CI})\end{array}$ & $\begin{array}{c}\text { Accuracy } \\
(95 \% \mathrm{CI})\end{array}$ & $\begin{array}{c}\text { AUROC } \\
(95 \% \mathrm{CI})\end{array}$ & $\begin{array}{c}\text { p-value } \\
(\text { Sig. })\end{array}$ \\
\hline hsCRP & $61.8 \%$ & $61.5 \%$ & $67.7 \%$ & $55.2 \%$ & $61.7 \%$ & 0.507 & 0.930 \\
$\leq 13.17 \mathrm{mg} / 1$ & $(43.6-77.8)$ & $(40.6-79.8)$ & $(48.6-83.3)$ & $(35.3-73.9)$ & $(42.3-78.7)$ & $(0.375-0.638)$ & $(\mathrm{NS})$ \\
\hline ProBNP & $58.8 \%$ & $65.4 \%$ & $69 \%$ & $54.8 \%$ & $61.7 \%$ & 0.626 & 0.086 \\
$>1581 \mathrm{pg} / \mathrm{ml}$ & $(40.7-75.4)$ & $(44.3-82.8)$ & $(49.2-84.7)$ & $(35.7-73)$ & $(42.3-78.6)$ & $(0.491-0.747)$ & $(\mathrm{NS})$ \\
\hline GDF-15 & $76.5 \%$ & $50 \%$ & $66.7 \%$ & $61.9 \%$ & $65 \%$ & 0.618 & 0.109 \\
$\leq 992.27 \mathrm{ng} / 1$ & $(58.8-89.3)$ & $(29.9-70.1)$ & $(49.5-81.1)$ & $(38.4-81.9)$ & $(46.3-81)$ & $(0.484-0.741)$ & $(\mathrm{NS})$ \\
\hline
\end{tabular}

Table (6): Markers of myocardial injury as diagnostic markers for ACS; ROC curve Analysis

\begin{tabular}{lccccccc}
\hline $\begin{array}{c}\text { Cut-off } \\
\text { values }\end{array}$ & $\begin{array}{c}\text { SN \% } \\
(95 \% \mathrm{CI})\end{array}$ & $\begin{array}{c}\text { SP } \% \\
(95 \% \mathrm{CI})\end{array}$ & $\begin{array}{c}\text { PPV \% } \\
(95 \% \mathrm{CI})\end{array}$ & $\begin{array}{c}\text { NPV \% } \\
(95 \% \mathrm{CI})\end{array}$ & $\begin{array}{c}\text { Accuracy } \\
(95 \% \mathrm{CI})\end{array}$ & $\begin{array}{c}\text { AUROC } \\
(95 \% \mathrm{CI})\end{array}$ & $\begin{array}{c}\text { p-value } \\
(\text { Sig. })\end{array}$ \\
\hline hsCRP & $80 \%$ & $100 \%$ & $100 \%$ & $62.5 \%$ & $85 \%$ & 0.923 & $<0.001$ \\
$>4.99 \mathrm{mg} / \mathrm{l}$ & $(67.7-89.2)$ & $(83.2-100)$ & $(92.6-100)$ & $(43.4-79.1)$ & $(71.6-91.9)$ & $(0.841-0.970)$ & $(\mathrm{HS})$ \\
\hline ProBNP & $93.3 \%$ & $100 \%$ & $100 \%$ & $83.3 \%$ & $95 \%$ & 0.968 & $<0.001$ \\
$>52.44 \mathrm{pg} / \mathrm{ml}$ & $(83.8-98.2)$ & $(83.2-100)$ & $(93.6-100)$ & $(62.1-95.4)$ & $(83.7-98.7)$ & $(0.903-0.995)$ & $(\mathrm{HS})$ \\
\hline GDF-15 & $60 \%$ & $80 \%$ & $90 \%$ & $40 \%$ & $65 \%$ & 0.650 & 0.018 \\
$>794.42 \mathrm{ng} / \mathrm{l}$ & $(46.5-72.4)$ & $(56.3-94.3)$ & $(76.1-97.3)$ & $(24.9-56.7)$ & $(49-77.9)$ & $(0.535-0.753)$ & $(\mathrm{S})$ \\
\hline
\end{tabular}

ROC curve: Receiver Operating Characteristic curve; SN: Sensitivity; SP: Specificity; PPV: Positive Predictive Value; NPV: Negative Predictive Value; AUROC: Area Under Receiver Operating Characteristic curve; 95\%CI: 95\% Confidence Interval; $\mathrm{p}<0.05$ is significant. 


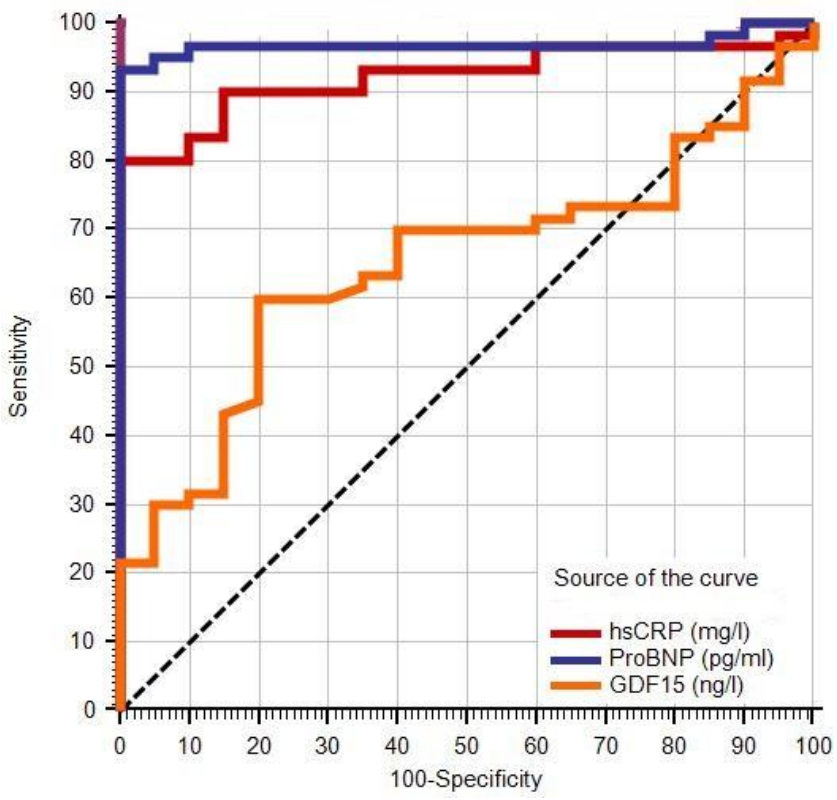

Fig. (1): Receiver operating characteristic (ROC) curve of markers of myocardial injury as diagnostic markers for ACS

\section{DISCUSSION}

This study focused on newer generation biomarkers in patients suffering acute coronary syndrome and their incremental value for risk stratification. So, the aim of this study is to evaluate the most important cardiac biomarker in risk evaluation in patients presenting by symptoms of cardiac ischemia. cTnT, HsCRP, proB-NP and GDF-15 will be assayed to correlate their levels with known clinical and angiographic risk factors.

cTnT median in group (I) with STEMI; $6450(\mathrm{pg} / \mathrm{ml})$ and group (II) with NSTEMI; $5345.5(\mathrm{pg} / \mathrm{ml})$ while the control group is within the normal range; $3.43(\mathrm{pg} / \mathrm{ml})$ which shows a statistically significant difference between group (I) and (II) and between group (I) and (III) and also between group (II) and (III).

As regard hsCRP, there was no statistical significant difference between patient groups (I) and (II) when compared to each other while there was significant difference between patient groups and control.

These results were in agreement with Scirica et al., $2007^{[4]}$ in the TIMI study group (which is one of the largest studies to investigate early determination of hsCRP in MI), who concluded that there was a statistically significant increase in hsCRP concentrations in patients with ACS versus control group.

As shown in table (4), a non-statistically significant difference was found between hsCRP levels and different number of affected coronary arteries in angiography.

These results regarding correlation between hsCRP levels and severity of angiographic findings were in agreement with those of the study done by Saleem and Ali, $2017^{[5]}$ which concluded that no significant correlation was found between CRP levels measured in patients with ACS and angiographically determined degree of stenosis and number of vessel involved.

As regard ProBNP, the median in group (I) was $1482(\mathrm{pg} / \mathrm{ml})$ and in group (II) was $1487.5(\mathrm{pg} / \mathrm{ml})$ while the control group was $17.66(\mathrm{pg} / \mathrm{ml})$. Statistically we found that there was a non-statistically significant difference between group (I) and (II) and there was a statistically significant difference between group (I) and (III); and a significant difference between group (II) and (III). 
Our results coincides with the study done by Goetze $2004^{[6]}$ who strongly suggests that acute myocardial hypoxia/ischemia per se stimulates BNP expression and the release of a newly synthesized proBNP peptide. In his study, NT-proBNP levels were markedly elevated in ACS patients, especially in the NSTE-ACS group. Therefore, pro-BNP and could be an early sensitive marker of myocardial ischemia that rises much higher than expected than the cardiac troponin levels in NSTE-ACS patients, and even in the absence of heart failure ${ }^{[6]}$.

The study results were in agreement with (although P-value did not reach statistical significance) those of Zdravkovic et al. $2013^{[7]}$ study which found that values of NT-proBNP were significantly higher in the NSTE-ACS than in the STE-ACS group. Galvani et al. $2004^{[8]}$ reported similar findings in their multicentre study of patients with ACS.

In comparing both groups STEMI and NSTEMI regarding the number of vessels affected we found that more than one vessel appears to occur in a higher percent of NSTEMI patients $(50 \%)$ in relation to $(16.7 \%)$ of STEMI patients.

These findings were in agreement with Chan et al., $2009^{[9]}$ which mentioned that their angiographic data showed that patients with NSTEMI had a greater prevalence of doubleand triple-vessel disease compared with patients with STEMI. Although they did not assess recurrent ischemia, they hypothesized that the greater CAD severity among NSTEMI patients compared with STEMI patients may have led to more recurrent ischemia.

Also, the above findings agrees with those of the study done by Miyachi et al., 2016 ${ }^{[10]}$ whom stated that $(55.2 \%)$ of their NSEMI cases had multi vessel diseases, and almost the same proportion of STEMI patients $(55.4 \%)$ had single vessel disease. This study attributed its findings to that NSTEMI patients tended to have more extensive medical histories, including more cardiovascular events and coronary risk factors, than STEMI patients. Nevertheless, NSTEMI patients tended to receive in-hospital pharmacological therapies and undergo PCI less frequently than STEMI patients. Moreover, Miyachi et al., $2016^{[10]}$ stated that these tendencies are not unique to Tokyo CCU network and are similar to many registries in Japan and other countries.

As regard Growth Differentiation Factor15 (GDF-15), the median in group (I) was 873.89 (ng/l) and in group (II) was 820.3 (ng/l) while the control group was 757.73 (ng/l). During comparing the three groups statistically, we found that there was a non-statistical significant difference between them.

Regarding GDF-15 levels in both patient groups (I) \& (II), the study results showed agreement with the one done by Khan et al., 2009 [11] which stated that there was no significant difference in GDF15 levels in STEMI versus NSTEMI cases.

On the other hand, regarding GDF-15 levels in all AMI cases this study results disagrees with Khan et al., 2009 as it showed significantly elevated GDF-15 levels which could be attributed to larger number of cases and different timing of plasma sampling.

Patients with a longer duration of hospitalization showed increased level of GDF15 compared with patients with an earlier discharge date ${ }^{[12]}$. With respect to their prognostic value, the measurement of GDF-15 levels after AMI may enhance standard tools already used in clinical practice and may be useful in detection of patients prone to longer hospitalization and at risk for developing newonset or worsening heart failure [13], which needs longer durations of follow up that was not available in this study.

Accordingly, one feasible explanation for the predictive role of GDF-15 is that higher levels of GDF-15 indicate a greater extent of myocardium damage and the risk of adverse remodeling. GDF-15 is also strongly induced in other cardiovascular conditions, such as heart failure ${ }^{[14]}$.

\section{CONCLUSION}

All studied biochemical markers except GDF15 showed a statistically significant difference between cases and controls, while 
only troponin $\mathrm{T}$ showed a statistically significant difference between both patient groups.

\section{REFERENCES}

1. Meredith AJ, Dai DL, Chen V, Hollander Z, $\mathrm{Ng} \mathrm{R}$, et al. (2016): Circulating biomarker responses to medical management vs. mechanical circulatory support in severe inotrope-dependent acute heart failure. ESC Heart Fail; 2016; 3(2):86-96.

2. Bodi V, Sanchis J, Morales JM, Marrachelli VG, Nunez J, et al. (2012): Metabolomic profile of human myocardial ischemia by nuclear magnetic resonance spectroscopy of peripheral blood serum: a translational study based on transient coronary occlusion models. J. Am. Coll. Cardiol.;2012; 59: 1629-1641.

3. Karki P, Agrawaal KK, Lamsal M, Shrestha NR (2015): Predicting outcomes in acute coronary syndrome using biochemical markers. Indian Heart J.;2015; 67(6):529-37.

4. Scirica B, Marrow D, Cannon C, et al., (2007): Clinical application of CRP across the spectrum of acute coronary syndromes. Clinical chemistry;2007; 10: 1800-1807.

5. Saleem A and Ali A (2017): Correlation of Creactive protein and cardiac enzymes with angiographic severity of coronary artery disease in Pakistani patients with acute coronary syndrome. Journal of the college of physicians and surgeons Pakistan; 2017; 27 (2): 66-70.

6. Goetze JP, Gore A, Moller CH, et al. (2004): Acute myocardial hypoxia increases BNP gene expression. FASEB J; 2004; 18: 1928-1930.

7. Zdravkovic V, Mladenovic V, Colic M, Bankovic D, Lazic Z, et al. (2013): NTproBNP for prognostic and diagnostic evaluation in patients with acute coronary syndromes. Kardiol Pol.; 2013; 71(5): 472-479.
8. Galvani M, Ottani F, Oltrona L et al. (2004): Italian Working Group on Atherosclerosis, Thrombosis, and Vascular Biology and the Associazione Nazionale Medici Cardiologi Ospedalieri (ANMCO). N-terminal pro-brain natriuretic peptide on admission has prognostic value across the whole spectrum of acute coronary syndromes. Circulation; 2004; 110: 128-134.

9. Chan M, Sun J, Newby L, et al. (2009): Long term mortality of patients undergoing cardiac catheterization for ST-elevation and non-STelevation myocardial infarction. Circulation; 2009; 119: 3110-3117.

10. Miyachi H, Takagi A, Miyauchi $K$, et al. (2016): Current charachteristics and management of ST elevation and non-ST elevation myocardial infarction in the Tokyo metropolitan area: from the Tokyo CCU network registered cohort. Heart Vessels; 2016; 31: 1740-1751.

11. Khan S, Ng K, Dhillon O, et al. (2009): Growth differentiation factor-15 as a prognostic marker in patients with acute myocardial infarction. Eur Heart J; 2009; 30:1057-1065.

12. Schernthaner C, Lichtenauer M, Wernly B, Paar V, Pistulli R, et al. (2017): MultiBiomarker Analysis in Patients with Acute Myocardial Infarction. Eur J Clin Invest; 2017;Jul6.doi: 10.1111/eci.12785. [Epub ahead of print]

13. O'Donoghue ML, Morrow DA, Cannon CP, Jarolim P, Desai NR, et al. (2016): Multimarker Risk Stratification in Patients With Acute Myocardial Infarction. J Am Heart Assoc;2016; pii: e002586.

14. Kempf T, Zarbock A, Widera C, et al. (2011): GDF15 is an inhibitor of leukocyte integrin activation required for survival after myocardial infarction in mice. Nat med.; 2011; 17(5): 581-588. 